\title{
Protective mechanical ventilation in suspected influenza infection
}

\author{
Letícia Brito Mendes Pimenta ${ }^{[1]}$, Nicole Zanzarini Sanson ${ }^{[2],}$ Márcia Souza Volpe ${ }^{[3],}$ \\ Marcelo Britto Passos Amato ${ }^{[4]}$, Adilha Misson Rua Micheletti ${ }^{[5]}$ \\ and Luciana de Almeida Silva Teixeira ${ }^{[6]}$
}

[1]. Universidade Federal do Triângulo Mineiro, Programa de Pós-Graduação Stricto Sensu em Medicina Tropical e Infectologia, Uberaba, MG, Brasil.

[2]. Universidade Federal do Triângulo Mineiro, Curso de Graduação em Medicina, Uberaba, MG, Brasil.

[3]. Universidade Federal de São Paulo, Campus Baixada Santista, Departamento de Ciências do Movimento Humano, Santos, SP, Brasil.

[4]. Universidade de São Paulo, Divisão Pulmonar, Departamento de Cardiopneumologia, São Paulo, SP, Brasil.

[5]. Universidade Federal do Triângulo Mineiro, Departamento de Clínica Cirúrgica, Uberaba, MG, Brasil.

[6]. Universidade Federal do Triângulo Mineiro, Departamento de Clínica Médica, Uberaba, MG, Brasil.

\begin{abstract}
Introduction: Patients with acute respiratory failure due to influenza require ventilatory support. However, mechanical ventilation itself can exacerbate lung damage and increase mortality. Methods: The aim of this study was to describe a feasible and protective ventilation protocol, with limitation of the tidal volume to $\leq 6 \mathrm{~mL} / \mathrm{kg}$ of the predicted weight and a driving pressure $\leq 15 \mathrm{cmH} \mathrm{O}_{2}$ after application of the alveolar recruitment maneuver and PEEP titration. Results: Initial improvement in oxygenation and respiratory mechanics were observed in the four cases submitted to the proposed protocol. Conclusions: Our results indicate that the mechanical ventilation strategy applied could be optimized.
\end{abstract}

Keywords: Acute respiratory distress syndrome. Influenza virus. Mechanical ventilation.

Approximately $60-88 \%$ of patients admitted to intensive care units (ICUs) with respiratory complications resulting from influenza virus infection require mechanical ventilation. Among those patients who develop acute respiratory distress syndrome (ARDS), 21-48\% die ${ }^{1}$.

Mortality in patients with ARDS as a complication of influenza is mainly related to the difficulty in ventilating them. Severe hypoxemia refractory to conventional strategies of mechanical ventilation is frequently observed. Furthermore, divergences in ventilatory parameters are found, and there is no protocol that ensures protective mechanical ventilation to this population. There have been no clinical trials, and the results of case and protocol studies are inconclusive, especially regarding the use of alveolar

\footnotetext{
Corresponding author: Letícia Brito Mendes Pimenta.

e-mail: leticiabmcosta@hotmail.com

(D)https://orcid.org/0000-0001-5802-0184

Received 16 October 2019

Accepted 28 May 2020
}

recruitment maneuvers (ARM) and the adjustment of protective positive end-expiratory pressure $(\mathrm{PEEP})^{2,3}$.

In our institution, in the past three years, 20 patients with a confirmed diagnosis of influenza required mechanical ventilation. More than $80 \%$ of cases were ventilated with high tidal volumes ( $>8 \mathrm{~mL} / \mathrm{kg}$ of the predicted body weight [PBW]) and fractions of inspired oxygen $\left(\mathrm{FiO}_{2}\right) \geq 0.6$ for a period longer than $48 \mathrm{~h}$. Recruitment maneuvers and titration of optimal PEEP were performed in only $35 \%$ of the cases, and the mean PEEP was 13 $\mathrm{cmH}_{2} \mathrm{O}$. The mortality rate was $80 \%$.

In light of this scenario, the objective of the present study was to describe the application of a feasible and protective mechanical ventilation strategy in patients with suspicion of ARDS caused by influenza. The mechanical ventilation strategy applied aimed to reduce mechanical stresses on the lung - minimization of alveolar collapse and hyperdistension - by using low tidal volumes, limiting the delta pressure, and setting the optimal PEEP after ARM.

This study was approved by the Ethics Committee of Universidade Federal do Triângulo Mineiro (UFTM) (CAEE: 2.651.578) 
and was conducted at the 12-bed ICU of the university hospital of UFTM. The inclusion criteria were: age $\geq 18$ years; suspicion of ARDS due to influenza (classification of the Brazilian Ministry of Health $)^{4}$; use of oseltamivir for less than $48 \mathrm{~h}$; and receiving mechanical ventilation for less than $48 \mathrm{~h}$. The exclusion criteria were: failure of more than 3 organs evaluated using APACHE II; hemodynamic instability (mean arterial pressure $<60 \mathrm{mmHg}$ or need for noradrenaline $>2 \mathrm{mg} / \mathrm{kg} / \mathrm{min}$ ); previous diagnosis of heart failure functional class 3 or 5 ; and acute brain injury.

Measurements of respiratory mechanics, ventilatory parameters, arterial blood gas parameters, length of ICU and hospital stay, duration of mechanical ventilation, and clinical outcomes at 28 days were evaluated.

The protective strategy consisted of limiting the tidal volume to $\leq 6 \mathrm{~mL} / \mathrm{kg}$ of the PBW and driving pressure (plateau pressure minus PEEP) to $\leq 15 \mathrm{cmH}_{2} \mathrm{O}$ after the application of ARM and adjustment of PEEP according to the titrated value. During ARM and PEEP titration, all patients were sedated with fentanyl and midazolam, in addition to neuromuscular block with cisatracurium hydrochloride. ARM was performed in the pressure-controlled ventilation mode with a driving pressure of $15 \mathrm{cmH}_{2} \mathrm{O}$. An initial PEEP of $10 \mathrm{cmH}_{2} \mathrm{O}$ was set, with increments of $5 \mathrm{cmH}_{2} \mathrm{O}$ every minute until $30 \mathrm{cmH}_{2} \mathrm{O}$ was reached, lasting 5 minutes. Decremental PEEP titration was then started at 25 $\mathrm{cmH}_{2} \mathrm{O}$, with a decrease in PEEP of $2 \mathrm{cmH}_{2} \mathrm{O}$ every minute until 5 $\mathrm{cmH}_{2} \mathrm{O}$. Static compliance of the respiratory system was measured in each decremental step. At the end of PEEP titration, a new ARM was performed, and PEEP was adjusted to the value that produced the best respiratory compliance ${ }^{5}$, followed by adjusting the tidal volume at $\leq 6 \mathrm{~mL} / \mathrm{kg}$ of the PBW and the driving pressure at $\leq 15 \mathrm{cmH}_{2} \mathrm{O}$.

The patient was classified as responsive to the maneuver if a reduction in the driving pressure $\geq 3 \mathrm{cmH}_{2} \mathrm{O}$ occurred. In the case of accidental disconnection of the ventilator or the patient required $\mathrm{FiO}_{2} \geq 80 \%$ for oxygen saturation $\geq 92 \%$, a new $\mathrm{ARM}$ and decremental PEEP titration were performed.

In the case of refractory hypoxemia $\left(\mathrm{PaO}_{2} \leq 60 \mathrm{mmHg}\right.$ for at least $6-8 \mathrm{~h}$ in the presence of $100 \% \mathrm{FiO}_{2}$ ), refractory acidosis $(\mathrm{pH} 7.1$ for at least $1 \mathrm{~h}$ ), or refractory barotrauma (persistent pneumothorax with 2 drains on the affected side or increase in subcutaneous or mediastinal emphysema with 2 chest drains), rescue therapy in the prone position for $16 \mathrm{~h}$ was used, accompanied by a new maximum recruitment maneuver and decremental PEEP titration, which was maintained until the $\mathrm{PaO}_{2} / \mathrm{FiO}_{2}$ ratio was $\geq 150$ with $\mathrm{FiO}_{2} \leq 0.6$ and PEEP $\leq 10 \mathrm{cmH}_{2} \mathrm{O}$ in the supine position.

For ventilatory weaning, we first reduced $\mathrm{FiO}_{2}$ to 0.4 and then PEEP by $2 \mathrm{cmH}_{2} \mathrm{O}$ every $24 \mathrm{~h}$ until it was between $12-16 \mathrm{cmH}_{2} \mathrm{O}$. If the tidal volume of the patient was $\geq 9 \mathrm{~mL} / \mathrm{kg}$ of the $\mathrm{PBW}$, weaning was not continued and administration of Precedex may have been necessary. Extubation occurred at a PEEP of $12 \mathrm{cmH}_{2} \mathrm{O}$ and pressure support of $7 \mathrm{cmH}_{2} \mathrm{O}$. Noninvasive ventilation with a PEEP of $12 \mathrm{cmH}_{2} \mathrm{O}$ was used in the first 24-48 $\mathrm{h}$ after extubation and was maintained as long as possible in the first $24 \mathrm{~h}$, followed by progressive reduction.

Between January 2018 and August 2019, 32 patients with suspected influenza were admitted to the UFTM university hospital, 12 of them required ventilatory support and 4 were eligible for the study.
The characteristics, mechanical ventilator parameters, and progression of the four patients are shown in Table 1. The APACHE II score for the evaluation of initial disease severity was $19 \pm 6$. All patients received oseltamivir within 2-5 days after the onset of symptoms. The two patients with a laboratory confirmation of influenza by RT-PCR died. During the ARM and PEEP titration, none of the patients exhibited hemodynamic alterations allowing completion of the protocol. Table 1 also shows the $\mathrm{PaO}_{2} / \mathrm{FiO}_{2}$ ratio and PEEP and driving pressure before and $2 \mathrm{~h}$ after the application of the protocol. An noticeable increase in the $\mathrm{PaO}_{2} / \mathrm{FiO}_{2}$ ratio was observed in three of the four patients, while patient 3 exhibited a slight reduction. The titrated PEEP was 13 and $17 \mathrm{cmH}_{2} \mathrm{O}$ in the confirmed cases of influenza infection, while the values were much lower, 5 and $7 \mathrm{cmH}_{2} \mathrm{O}$, in the unconfirmed cases. Interestingly, except for patient 3, the titrated PEEP was lower than the initially adjusted value. With respect to lung recruitability, a driving pressure reduction by $2 \mathrm{cmH}_{2} \mathrm{O}$, immediately after the protocol application, was only possible in two cases.

Regarding static and dynamic compliance, patients who died had substantially lower values than the normal range. The plateau pressure remained within the protective limits, except for the last measurement of patient 4 moments before death. Airway resistance remained high in two cases (Table 2). Despite improvements of the $\mathrm{PaO}_{2} / \mathrm{FiO}_{2}$ ratio, the respiratory mechanics of these patients were compromised, a fact that may be associated with the physiopathogenesis of the disease and its progression to death.

Oxygenation continued to improve in patients 1,2 , and 3, but not in patient 4. Patient 2 showed marked improvement in the first 5 days, but important clinical worsening was observed after accidental extubation, and on day 17 she died. The driving pressures were maintained within the protective range in all cases.

Figure 1 shows the lung images of patients 2 and 4 before and after the mechanical ventilation protocol was applied. There was a marked improvement on the chest X-ray of patient 2, but not patient 4 . The use of a real-time lung monitoring tool such as electrical impedance tomography may have helped to individualize the mechanical ventilation strategy applied to patient 4, allowing for better resolution of lung collapse/consolidation (Figure 1).

Influenza A virus is an important causative agent of acute respiratory disease ${ }^{3}$, which can result in ARDS and the need for ventilatory support. However, studies confirm that mechanical ventilation can exacerbate preexisting lung damage or even cause pulmonary injury itself ${ }^{7}$. This injury occurs during alveolar hyperdistension and cyclic opening and collapse of the alveoli. In addition, the mechanical stimulus is converted to biomolecular activity through mechanotransduction, which triggers the release of a range of inflammatory mediators and neutrophil infiltration. Ultimately, these events lead to multi-organ dysfunction and death ${ }^{8}$.

Cornejo et al. ${ }^{2}$ and Venkategowda et al. ${ }^{3}$ demonstrated that protective mechanical ventilation strategies using low tidal volumes improved outcomes among patients with ARDS after influenza infection. In addition, high levels of PEEP and ARM have been used to improve oxygenation, opening collapsed alveoli, and allowing a more homogenous distribution of ventilation ${ }^{2,9}$. Analysis of recruitability in the present study showed that it was not possible in any of the cases to reduce the driving pressure by $3 \mathrm{cmH}_{2} \mathrm{O}$, the 
TABLE 1: Clinical characteristics and mechanical ventilator parameters of patients submitted to the protective mechanical ventilation protocol.

\begin{tabular}{|c|c|c|c|c|}
\hline Parameters & Patient 1 & Patient 2 & Patient 3 & Patient 4 \\
\hline Age (years) & 63 & 52 & 65 & 68 \\
\hline Sex & M & $\mathrm{F}$ & M & M \\
\hline Comorbidities & $\begin{array}{l}\text { SAH, chronic AF, } \\
\text { Hypothyroidism, RTV }\end{array}$ & SAH, obesity & Smoking: 15.9 pack-years & $\begin{array}{c}\text { Hypogonadotropic } \\
\text { hypogonadism, aortic and } \\
\text { tricuspid regurgitation, hepatic } \\
\text { steatosis, CRF, nephrolithiasis }\end{array}$ \\
\hline APACHE II & 25 & 17 & 9 & 25 \\
\hline Hemodialysis & Yes & Yes & No & No \\
\hline Secondary infections & Bacterial PNM & Bacterial PNM & Bacterial PNM & Bacterial PNM \\
\hline Vaccination & No & No & No & Yes \\
\hline Influenza confirmation & No & Yes & No & Yes \\
\hline Corticosteroids & Yes & Yes & No & Yes \\
\hline Antiviral & Oseltamivir & Oseltamivir & Oseltamivir & Oseltamivir \\
\hline $\begin{array}{l}\text { Interval between symptom } \\
\text { onset and beginning of antiviral } \\
\text { use (days) }\end{array}$ & 2 & 5 & 3 & 4 \\
\hline \multicolumn{5}{|l|}{ Ventilator parameters } \\
\hline \multicolumn{5}{|l|}{ PEEP $\left(\mathrm{cmH}_{2} \mathrm{O}\right)$} \\
\hline Basal & 14 & 16 & 12 & 15 \\
\hline $2 \mathrm{~h}$ after protocol completion & 7 & 17 & 5 & 13 \\
\hline \multicolumn{5}{|l|}{$\Delta \mathrm{P}\left(\mathrm{cmH}_{2} \mathrm{O}\right)$} \\
\hline Basal & 16 & 13 & 9 & 13 \\
\hline $2 \mathrm{~h}$ after protocol completion & 14 & 11 & 9 & 13 \\
\hline \multicolumn{5}{|l|}{$\mathrm{PaO}_{2} / \mathrm{FiO}_{2}$} \\
\hline Basal & 83.8 & 58.0 & 192.0 & 91.4 \\
\hline $2 \mathrm{~h}$ after protocol completion & 154 & 104.0 & 184.0 & 151.0 \\
\hline Number of ARM & 3 & 3 & 1 & 3 \\
\hline Duration of MV (days) & 25 & 17 & 6 & 4 \\
\hline Length of ICU stay (days) & 26 & 17 & 12 & 5 \\
\hline Length of hospital stay (days) & 61 & 17 & 30 & 5 \\
\hline Clinical outcome & Discharged & Death & Discharged & Death \\
\hline
\end{tabular}

Legend: M: male; F: female; MV: mechanical ventilation; ARM: alveolar recruitment maneuver; ICU: intensity care unit; SAH: systemic arterial hypertension; AF: atrial fibrillation; RTV: virus HIV; CRF: chronic renal failure; PNM: pneumonia; $\mathrm{PEEP}$ : positive end-expiratory pressure; $\Delta \mathrm{P}$ : driving pressure; $\mathrm{PaO}_{2} / \mathrm{FiO}_{2}$ ratio of partial pressure arterial oxygen and fraction of inspired oxygen. 
TABLE 2: Parameters of respiratory mechanics in patients who died.

\begin{tabular}{|c|c|c|c|c|c|c|c|c|}
\hline \multirow{2}{*}{ Parameter } & \multicolumn{2}{|c|}{ Before protocol } & \multicolumn{2}{|c|}{ After $24 \mathrm{~h}$} & \multicolumn{2}{|c|}{ After $48 \mathrm{~h}$} & \multicolumn{2}{|c|}{ After $72 \mathrm{~h}$} \\
\hline & Patient 2 & Patient 4 & Patient 2 & Patient 4 & Patient 2 & Patient 4 & Patient 2 & Patient 4 \\
\hline $\begin{array}{l}\text { Cst }\left(\mathrm{mL} / \mathrm{cmH}_{2} \mathrm{O}\right) \\
\text { RR: } 60-100\end{array}$ & 29 & 25 & 26 & 20 & 30 & 26 & 38 & 21 \\
\hline $\begin{array}{l}\text { Cdyn }\left(\mathrm{mL} / \mathrm{cmH}_{2} \mathrm{O}\right) \\
\text { RR: } 50-80\end{array}$ & 23 & 21 & 23 & 24 & 25 & 18 & 31 & 16 \\
\hline $\begin{array}{l}\text { Raw }\left(\mathrm{cmH}_{2} \mathrm{O} / / / \mathrm{s}\right) \\
\text { RR: } 2-5\end{array}$ & 14 & 19 & 13 & 23 & 17 & 15 & 16 & 16 \\
\hline
\end{tabular}

Legend: Cst: static compliance; Cdyn: dynamic compliance; AWR: airway resistance; RR: reference range. Source: Opasich et al6.

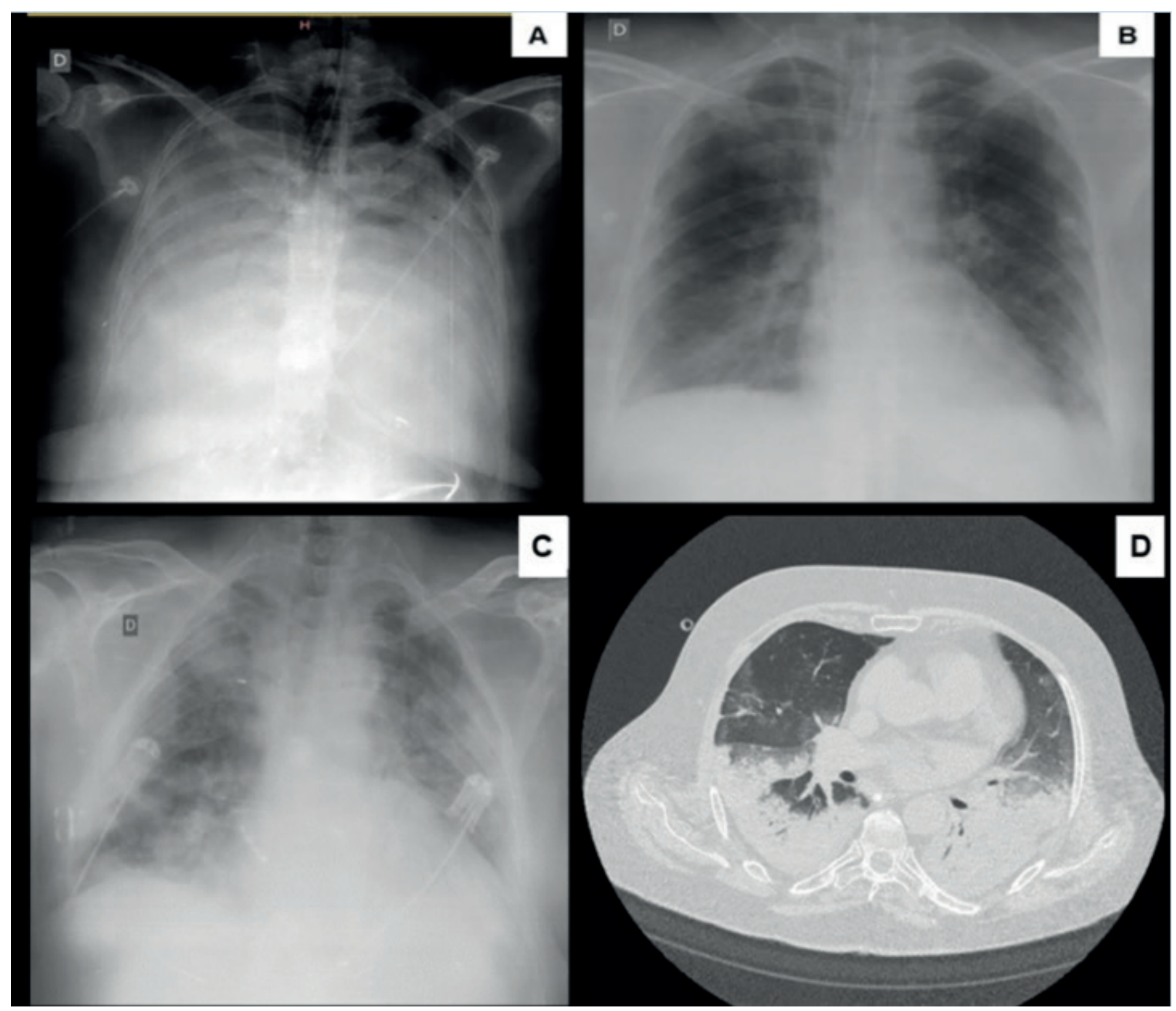

FIGURE 1: Chest images of patient 2 (A and B) and patient 4 (C and D). A and C images were obtained before the protective mechanical ventilation protocol was started and $\mathbf{B}$ and $\mathbf{D}$ images 24 to $48 \mathrm{~h}$ after initiation of the protocol. Note that patient 2 showed a marked improvement on chest $\mathrm{X}$-ray after the protocol was applied, whereas patient 4 did note. Computed tomography scan (D) showed extensive lower lobe consolidations related to the inflammatory/infectious process associated with ground-glass attenuation, which may represent an edema component. 
reference value defined for responsiveness to recruitment. A possible explanation for this finding is that the patients already exhibited safe driving pressures before the start of the protocol. Evidence indicates that patients with high driving pressures respond best to protective strategies ${ }^{10}$. However, initial improvement in oxygenation was observed in most patients. The optimal PEEP found in the confirmed cases was relatively high ( 13 and $17 \mathrm{cmH}_{2} \mathrm{O}$ ), similar to other reports ${ }^{4,8}$. It must be stressed that in three patients the titrated PEEP was lower than the initially adjusted PEEP, a finding which illustrated the complexity of protective ventilation in these patients.

Both patients with confirmed infection died. The presence of comorbidities is recognized as a risk factor for severe outcomes in patients infected with influenza ${ }^{11}$. Comorbidities were found in all patients of the study. The early initiation of treatment with antiviral medication (within $48 \mathrm{~h}$ ) is considered a protective factor ${ }^{12}$. In the patients with fatal outcomes, treatment was initiated late (about 4-5 days after the onset of symptoms).

Laboratory tests for the diagnosis of influenza have limitations that can produce misleading results. In our cases, RT-PCR was used, which shows a sensitivity around $80.0 \%$ and specificity of $95 \%{ }^{13}$. However, we cannot definitively rule out that patients without laboratory confirmation did not actually have influenza viral infection. We therefore included two patients without laboratory confirmation.

Despite the small sample size, the reported findings are considered relevant. There is a lack of trials on mechanical ventilation involving patients with influenza and this study provides some insight on how to apply a protective mechanical ventilation strategy to this population. The use of a real-time lung monitoring tool to individualize the ventilation strategy, such as electrical impedance tomography, may help to optimize the proposed strategies.

\section{ACKNOWLEDGMENTS}

We are in debt to the staff of Hospital de Clinics of Universidad Federal do Triângulo Mineiro for their support during the protocol implementation and data collection.

\section{AUTHORS' CONTRIBUTION}

LBMP: methodology, investigation, writing-original draft preparation; NZS: investigation; MSV: methodology, writingreviewing and editing, supervision; MBPA: methodology; AMRM: investigation; and LAST: methodology, writing-reviewing and editing, supervision, investigation.

\section{CONFLICT OF INTEREST}

The authors declare that there is no conflict of interest.

\section{REFERENCES}

1. Rice TW, Rubinson L, Uyeki TM, Vaughn FL et al. Critical illness from 2009 pandemic influenza A (H1N1) virus and bacterial co-infection in the United States. Crit Care Med. 2012;40(5):1487-98. doi:10.1097/ CCM.0b013e3182416f23.

2. Cornejo R, Tobar E, Diaz G, Romero C. Systematic approach to severe respiratory failure due to novel A (H1N1) influenza. Minerva Anestesiologica. 2011;77(5):510-21.

3. Venkategowda PM, Rao SM, Harde YR, Raut MK, Mutkule DP, Munta $\mathrm{K}$, Rao MV. Prone position and pressure control inverse ratio ventilation in H1N1 patients with severe acute respiratory distress syndrome. Indian J Crit Care Med. 2016;20(1):44-9.

4. Brasil. Ministério da Saúde. Secretaria de Vigilância em Saúde. Departamento de Vigilância das Doenças Transmissíveis. Protocolo de tratamento de Influenza: 2017. Available at http://bvsms.saude.gov.br/. Accessed 2 August 2018.

5. Barbas CS, Ísola AM, Farias AM, Cavalcanti AB, Gama AM, Duarte AC, et al. Recomendações brasileiras de ventilação mecânica 2013. Parte I. Rev Bras Ter Intensiva. 2014;26(2):89-121.

6. Opasich C, De Feo S, Pinna GD, Furgi G, Pedretti R, Scrutinio D, et al. Distance walked in the 6-minute test soon after cardiac surgery: toward an efficient use in the individual patient. Chest. 2004;126(6):1796-801.

7. Acute Respiratory Distress Syndrome Network, Brower RG, Matthay MA, Morris A, Schoenfeld D, Thompson BT, Wheeler A. Ventilation with lower tidal volumes as compared with traditional tidal volumes for acute lung injury and the acute respiratory distress syndrome. The Acute Respiratory Distress Syndrome Network. N Engl J Med. 2000;342(18):1301-8.

8. Slutsky AS, Tremblay LN. Multiple system organ failure. Is mechanical ventilation a contributing factor? Am J Respir Crit Care Med. 1998;157(6 Pt 1):1721-5.

9. Villar J, Kacmarek RM, Pérez-Méndez L, Aguirre-Jaime A. A high positive end-expiratory pressure, low tidal volume ventilatory strategy improves outcome in persistent acute respiratory distress syndrome: A randomized, controlled trial. Crit Care Med. 2006;34(5):1311-8.

10. Zampieri FG, Costa EL, Iwashyna TJ, Carvalho CRR, Damiani LP, Taniguchi LU, et al. Heterogeneous effects of alveolar recruitment in acute respiratory distress syndrome: a machine learning reanalysis of the Alveolar Recruitment for Acute Respiratory Distress Syndrome Trial. Br J Anaesth. 2019;123(1):88-95. doi: 10.1016/j.bja.2019.02.026.

11. Coleman LB, Fadel SA, Fitzpatrick T, Thomas SM. Risk factors for serious outcomes associated with influenza illness in high-versus lowand middle-income countries: Systematic literature review and metaanalysis. Influenza Other Respir Viruses. 2018;12(1):22-9.

12. Miller PE, Rambachan A, Hubbard RJ, Li J, Meyer AE, Stephens P, et al. Supply of neuraminidase inhibitors related to reduced influenza A (H1N1) mortality during the 2009-2010 H1N1 pandemic: an ecological study. Influenza Other Respir Viruses. 2013;7(2):82-6.

13. Maignan M, Viglino D, Hablot M, Termoz Masson N, Lebeugle A, Collomb Muret R, et al. Diagnostic accuracy of a rapid RT-PCR assay for point-of-care detection of influenza A/B virus at emergency department admission: A prospective evaluation during the 2017/2018 influenza season. PLoS ONE. 2019; 14(5):e0216308. 